\title{
Simple spectrophotometric method for estimation of drugs using chloramine- $t$ and indigo caramine dye couple.
}

\author{
Sailaja Battu ${ }^{1}$, Venkateshwarlu Gandu ${ }^{*}$, Bhavani P Nenavathu ${ }^{2}$ \\ ${ }^{1}$ Department of Chemistry, Osmania University, Hyderabad, India \\ ${ }^{2}$ Department of Applied Sciences and Humanities, Indira Gandhi Delhi Technical University for Women, Delhi, India
}

\begin{abstract}
The five drugs viz., GEM, PHE, TRD, IMT, VRP were estimated using a simple, specific, accurate and precise UV-visible spectrophotometric method. These methods involve the addition of a known nexcess of Chloramine- $T$ to the drugs in acid medium followed by estimation of residual Chloramine- $T$ by reacting with a fixed amount of Indigo caramine dye and measuring the absorbance of the dye at 608 $\mathrm{nm}$. The calibration curves obeyed Beer's law over the concentration range of 3.0,5.5,6.5 $\mu \mathrm{g} \mathrm{mL} \mathrm{m}^{-1}$ of GEM; 2.5,3.69,5.01 $\mu \mathrm{g} \mathrm{mL}-1$ of PHE ; 2.0,3.5,7.5 $\mu \mathrm{g} \mathrm{mL}-1$ of TRD; 3.0,4.5,7.0 $\mu \mathrm{g} \mathrm{mL} \mathrm{mL}^{-1}$ of IMT; and 4.2,5.5,7.0 $\mu \mathrm{g} \mathrm{mL}-1$ of VRP were chosen. The methods that are developed were found to be suitable for the estimation of these drugs in bulk and their formulations. Several parameters such as linearity, accuracy, and precision, Limit of detection and Limit of quantification were considered for the analysis of results of the drugs and their corresponding validation were carried out statistically.
\end{abstract}

Keywords: Chloramine-T, Indigo caramine dye, Spectrophotometry, Gemifloxacin, Phenyl ephrine HCl, Tramadol, Imatinibemesyate, Verapamil.

Accepted on February 03, 2020

\section{Abbreviations:}

GEM: Gemifloxacin Mesylate; PHE: Phenyl Ephrine $\mathrm{HCl}$; TRD: Tramadol; IMT: Imatinibemesyate: VRP: Verapamil.

\section{Introduction}

GEM is chemically 7-((4Z)-3-(aminomethyl)-4-methoxyiminopyrrolidin-1-yl]-1- cyclopropyl-6-fluoro-4-oxo-1, 4 dihydro-1, 8- napththyridine-3-carboxylic acid (Figure 1). It has high affinity towards bacterial topoisomerase IV and is a fourthgeneration fluoroquinolone antibacterial agent. Owing to its anti-bacterial activity to both gram-positive and gramnegative, this compound is mainly used for the treatment of acute exacerbations of urinary tract infection, chronic bronchitis and pneumonia. This drug is not official in any pharmacopoeia. Analysis of the literature demonstrated that there are numerous analytical methods for the estimation of GEM is specified. The present work mainly aims to describe a simple and sensitive UV method for estimation of GEM in tablet formulation [1-9].

Phenylephrine hydrochloride ((R)-1-(3-hydroxyphenyl) 2(methylamino) ethanol hydrochloride, $\mathrm{C}_{9} \mathrm{H}_{13} \mathrm{O}_{2} \mathrm{~N}$. $\mathrm{HCl}$, (Figure 1) is a white crystalline powder, andbelongs to the group of medicines called sympathomimetics. It acts as a stimulator for alpha receptors in certain areas of the body. It is used locally, as decongestant, for non-specific and allergic conjunctivitis, sinusitis and nasopharyngitis [10-15].

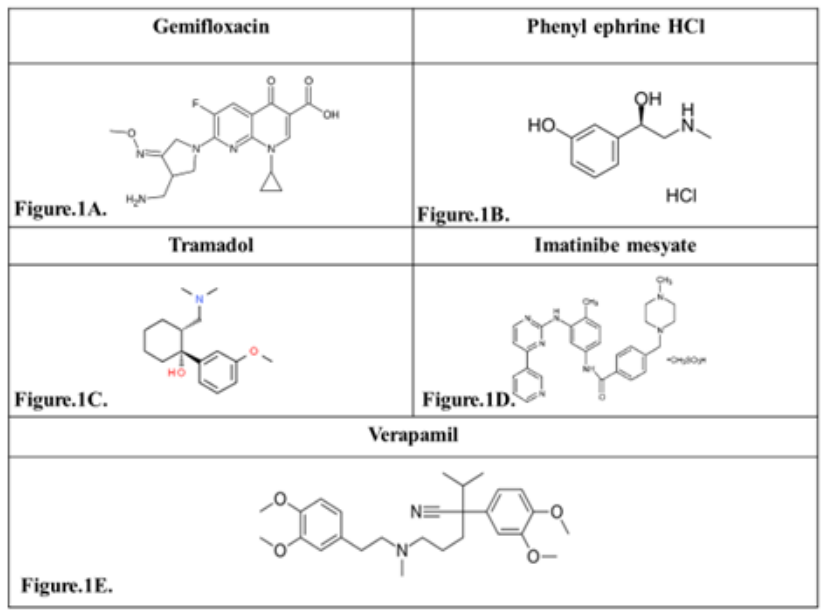

Figure 1. Structures of drugs.

Chemically Tramadol is (2-(dimethylaminomethyl)-1-(3methoxyphenyl) cyclohexanol) (Figure 1C). It possesses $\mu$ agonist activity. Tramadol hydrochloride is used for treating moderate to severe pain and is centrally acting analgesic and effects reuptake at the noradrenergic and serotonergic systems. Analysis of the literature demonstrates that there are few analytical methods reported for the determination of tramadol [16-23]. 
The Chemical name of Imatinib Mesylate is 4-4 ((4-methyl-1piperazinyl) methyl)-N-(4-methyl-3-((4-(3-pyridinyl)-2pyrimidinyl) amino) phenyl) -benzamide mono methane sulfonate (IMT). It has a molecular formula of $\mathrm{C}_{29} \mathrm{H}_{31} \mathrm{~N}_{7} \mathrm{O} . \mathrm{CH}_{4} \mathrm{O}_{3} \mathrm{~S}$ and a molecular weight of 589.71(Figure 1). Imatinib is used in the treatment of leukemia and gastrointestinal tumors and is a cancer medication. It controls the growth of the cancer cells by inhibiting the proteins involved in cancer cell growth, resulting in reducing the cancer symptoms, prevent the spread of cancer cells, and aids other treatment [24].

Verapamil chemically, (VRP) (RS)2(3,4dimethoxy phenyl $) 5$ \{(2(3,4 dimethoxyphenyl) ethymethyl)amino $\}$-2-prop2-ylpentanenitrile having molecular formula, C27H38N2O4 (Figure 1) belongs to Phenylalkylamine class and acts as a Ltype calcium channel blocker. It is used in the treatment of hypertension, angina pectoris, cardiac arrhythmia, and most recently, cluster headaches. It is highly effective in the prevention of migraine. During cryopreservation of blood vessels, VRP plays the role of a vasodilator. It belongs to class 4 antiarrhythmic and is more effectual in controlling ventricular rate compared with digoxin. British Pharmacopoeia contains the data corresponding to this drug and its formulations. For the assay of Verapamil in bulk and dosage forms, a gas chromatographic method was recommended by United States Pharmacopoeia and a non- aqueous titration method was given by Indian Pharmacopoeia. Several analytical methods for the determination of VRP are reported in the literature [25-34]. To the best of our knowledge, data for the estimation of above drugs using UV-Visible spectrophotometric method was not reported. The aim of the present work is to develop accurate, simple, sensitive, and costeffective method for the analysis of the above drugs.

\section{Materials and Methods}

\section{Reagents and standards}

The drugs of pharmaceutical grade were procured from Arabindo pharmaceuticals and Hetero drugs Pvt. Ltd. Hyderabad. Acidic Chloramine-T using Indigo Caramine dye and $\mathrm{HCl}$ were procured from S.D. Fine chem Pvt. Ltd., Mumbai, India. For proper filtration Whatman filter paper number 42 was used. All the chemicals and reagents were used without further purification and are of AR grade and throughout the investigation, double distilled water was used. Tablets were purchased from the local market.

\section{Instrumentation and optical characteristics}

The optical properties of as synthesized drug solutions were characterized by UV - visible spectrophotometer (Thermo Nicolet 100 and Elico 159) in the range of $200-800 \mathrm{~nm}$. For weighing the reagents a high precision Analytical balance was used.

\section{Preparation of standard stock solution}

A standard solution of $1.17 \times 10-3 \mathrm{M}$ was made by dissolving $0.033 \mathrm{gm}$ of Chloramine- $\mathrm{T}$ in $100 \mathrm{~mL}$ sterilised double distilled water. A standard solution of $1.23 \times 10-3 \mathrm{M}$ solution was made by dissolving $0.0325 \mathrm{gm}$ of Indigo caramine powder in $100 \mathrm{~mL}$ standard flask by using double distilled water. Standard drug stock solutions were prepared by dissolving 30 $\mathrm{mg}$ drug in to several $100 \mathrm{~mL}$ volumetric flasks. The stock solutions of GEM, HCl PHE, TRD, IMT, VRP were further diluted with the same solvent to attain working concentrations. Double distilled water was added properly to concentrate $\mathrm{HCl}$ to attain $2 \mathrm{M}$ acid solution.

\section{Construction of calibration curve}

A pure drug solution was prepared and its aliquots were transferred into a series of $10 \mathrm{~mL}$ calibrated flasks in the range of $(1.0-8.0 \mathrm{~mL})$. Further $2 \mathrm{M} \mathrm{HCl}$ was added to each flask and followed by addition of $1 \mathrm{Ml}$ oxidising agent which is Chloramine-T. The resultant solution was stirred for 10 minute under infrequent shaking. Finally, to each flask $1 \mathrm{~mL}$ of Indigo caramine dye solution was added and the volume was adjusted up to the mark with double distilled water and stirred well. The absorbance of as prepared samples was measured at $608 \mathrm{~nm}$ after 5 minutes. A standard graph was plotted using absorbance versus the concentration of drugs. Finally, the unknown samples concentration was measured from the calibration graph or computed from the regression equation derived using Beer' s law data. Calibration curve for each drug is drawn in Figure 2. The limits of Beer' $\mathrm{s}$ law, slope, intercept, correlation coefficient, sandell' $\mathrm{s}$ sensitivity and regression equation for each drug are tabulated in Tables 1 and 2 .
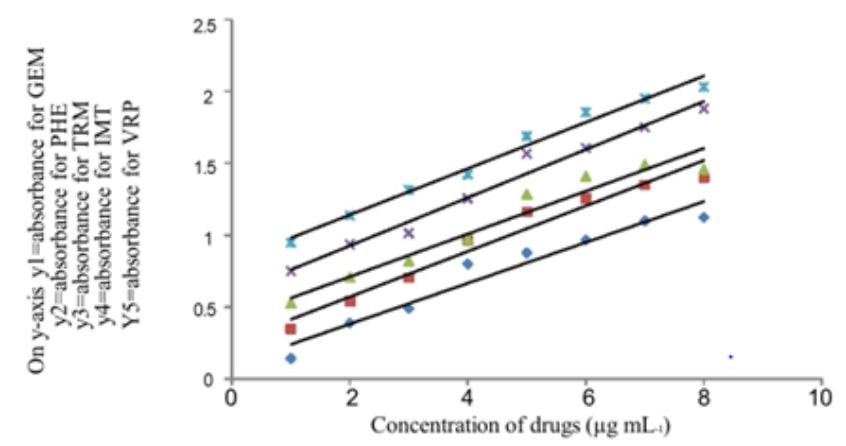

Figure 2. Calibration curves for drugs.

\section{Analysis of commercial dosage forms}

The following drugs such as GEM, PHE, TRD, IMT, VRP of $10 \mathrm{mg}$ each were finely ground in to powdered form from tablet form and weighed accurately and dispersed in $70 \mathrm{~mL}$ distilled water and then filtered through Whatman Number 42 filter paper. From the resultant filtrate, $10 \mathrm{~mL}$ was discarded and a suitable aliquot of filtrate was further diluted for the analysis within the limits of Beer' s law. 


\section{Validation}

Validation is a process of establishing documented evidence, which provides a high degree of assurance that a specific activity will consistently produce a desired result or product meeting its predetermined specifications and quality characteristics. Several parameters such as Linearity, Accuracy and Precision were validated for this method.

\section{Analytical Characteristics}

\section{Linearity}

The linearity of an analytical method is its ability to elicit test results that are directly or by a well-defined mathematical transformation proportional to the concentration of analyte in samples within a given range. Results should be expressed in terms of correlation co-efficient. From the data corresponding to the linearity, precision and accuracy, the range of analytical method can be obtained.

\section{Accuracy}

Accuracy of an analysis is determined by systemic error involved. It is defined as closeness of agreement between the actual (true) value and analytical value and obtained by applying test method for a number of times. Accuracy may often be expressed as Recovery by the assay of added amount of analyte. It determines the correctness of the analytical method.

\section{Precision}

The determination of the reproducibility of the proposed method was carried out using tablet assay at different time intervals on same (intra-day precision) and on three different days (inter-day precision). Results of intra-day precision are expressed in RSD. The corresponding data is presented in Table 3.

\section{Procedure for calibration}

A series of drug solution i.e. 1 to $7 \mathrm{~mL}$ of the drug solution was transferred in to separate $10 \mathrm{~mL}$ volumetric flasks. To these series of flasks add $2 \mathrm{M}$ acid solution followed by $1 \mathrm{~mL}$ of oxidising agent which is Chloramine-T. After 10 minute with occasional shaking, add $1 \mathrm{~mL}$ of Indigo caramine dye. Later the flasks were filled with double distilled water till the mark and shake well. Allow the flasks to measure at $608 \mathrm{~nm}$. For every individual drug a standard graph was prepared by plotting the absorbance versus the concentration of drugs and computation was carried out using regression equation derived using Beer's law. The concentration of a substance in an unknown sample is usually determined in analytical chemistry by plotting a calibration curve using a set of standard samples of known concentration and comparing with unknown concentration. The relative response of the drug is being calculated from the absorbance to concentration of the drug. The concentration of each drug was determined from a calibration graph constructed as shown in (Figure 2). Table 2 shows the limits of Beer's law, slope, intercept, correlation coefficient, sandell's sensitivity and regression equation for each drug.

\section{Procedure for assay of pure drugs}

Pure drug sample solutions containing drug in the Beer's law limit were chosen, in order to test the accuracy and precision of the methods developed.

\section{Results and Discussion}

\section{Method validation}

The following factors such as accuracy, limit of detection, limit of quantification, linearity, selectivity and ruggedness were considered for quantification of drugs using each method. All analyses were carried out in triplicate for analyzing the precision and percent recovery and percent RSD were considered for accuracy. The values for each drug are less than 2, which confirm that the methods developed are of high accuracy and precision. The values of F-test and t-test were further calculated using a standard reference method. From the Table 3 It is clear that the values of t-test and F-test are below the allowable range. This confirms the the exceptional applicability of the methods for pharmaceutical analysis.

Table 1. The range of concentration of the drugs used for Oxidation with Chloramine-T and Indigo caramine.

\begin{tabular}{lll}
\hline Drugs & $\begin{array}{l}\text { Working } \\
\text { concentration }\end{array}$ & Range \\
\hline Gemifloxacin & $7 \mu \mathrm{gL}^{-1}$ & $7-56 \mu \mathrm{g} \mathrm{mL}^{-1}$ \\
\hline Phenyl ephrine $\mathrm{HCl}$ & $10 \mu \mathrm{g} \mathrm{mL}^{-1}$ & $10-80 \mu \mathrm{g} \mathrm{mL}^{-1}$ \\
\hline Tramadol & $3 \mu \mathrm{g} \mathrm{mL}^{-1}$ & $3-24 \mu \mathrm{gL}^{-1}$ \\
\hline Imatinibemesyate & $8 \mu \mathrm{gL}^{-1}$ & $8-6.4 \mu \mathrm{g} \mathrm{mL}^{-1}$ \\
\hline Verapamil & $1.2 \mu \mathrm{g} \mathrm{mL}^{-1}$ & $1.2-9.6 \mu \mathrm{g} \mathrm{mL}^{-1}$ \\
\hline
\end{tabular}

Table 2. Analytical parameters for the oxidation of the drugs used for Oxidation with Chloramine-T and Indigo caramine.

\begin{tabular}{|c|c|c|c|c|c|c|c|c|c|}
\hline Parameter & GEM & & PHE & & TRD & & IMT & & VRP \\
\hline$\lambda \max ,(\mathrm{nm})$ & 611 & & 611 & & 611 & & 611 & & 611 \\
\hline $\begin{array}{l}\text { Beer's law } \\
\text { limits } \\
\left(\mu \mathrm{g} \mathrm{mL}^{-1}\right)\end{array}$ & $7-56$ & & $10-80$ & & $3-24$ & & $8-64$ & & $12-96$ \\
\hline $\begin{array}{l}\text { Molar } \\
\text { absorptivity } \\
\left(\mathrm{Lmol}^{-1} \mathrm{~cm}^{-1}\right)\end{array}$ & $\begin{array}{l}0.0787 \\
10^{5}\end{array}$ & $x$ & $\begin{array}{l}0.0348 \\
10^{5}\end{array}$ & $x$ & $\begin{array}{l}0.1106 \\
10^{4}\end{array}$ & $x$ & $\begin{array}{l}0.0919 \\
10^{5}\end{array}$ & $x$ & $\begin{array}{l}0.055 \\
10^{5}\end{array}$ \\
\hline $\begin{array}{l}\text { Sandell } \\
\text { sensitivity }\end{array}$ & 0.007 & & 0.0063 & & 0.0067 & & 0.0059 & & 0.0062 \\
\hline Slope, (b) & 0.1422 & & 0.1583 & & 0.149 & & 0.167 & & 0.161 \\
\hline $\begin{array}{l}\text { Correlation } \\
\text { Coefficient, } r\end{array}$ & 0.9486 & & 0.9608 & & 0.145 & & 0.976 & & 0.983 \\
\hline
\end{tabular}




\begin{tabular}{llllll}
\hline $\begin{array}{l}\text { Standard } \\
\text { deviation of } \\
\text { intercept (Sa) }\end{array}$ & 0.0301 & 0.0351 & 0.1486 & 0.0224 & 0.0159 \\
\hline $\begin{array}{l}\text { Limit of } \\
\text { detection } \\
\left(\mu \mathrm{mL}^{-1}\right)\end{array}$ & 0.5198 & 0.763 & 1.14 & 0.44 & 0.323 \\
$\begin{array}{l}\text { Limit of } \\
\text { quantification } \\
\left(\mu \mathrm{mL}^{-1}\right)\end{array}$ & 1.575 & 2.31 & 3.47 & 1.34 & 0.9802 \\
\hline
\end{tabular}

Table 3. Application of proposed method for the estimation of accuracy and precision by oxidation using Chloramine-T and Indigo caramine.

\begin{tabular}{|c|c|c|c|c|c|c|}
\hline Drug & $\begin{array}{l}\text { Taken } \\
\left(\mu \mathrm{gL}^{-1}\right)\end{array}$ & $\begin{array}{l}\text { Found } \\
\left(\mu \mathrm{g} \mathrm{mL}^{-1}\right)\end{array}$ & $\begin{array}{l}\mathrm{Er} \\
()\end{array}$ & $\begin{array}{l}\text { Recover } \\
\text { y } \\
()\end{array}$ & $\begin{array}{l}\text { RSD } \\
()\end{array}$ & $\begin{array}{l}\text { Proposed } \\
\text { method mean } \\
\pm \text { SD }\end{array}$ \\
\hline \multirow[t]{3}{*}{ GEM } & 3 & 3.011 & 0.366 & 100.36 & 0.138 & $100.14 \pm 0.137$ \\
\hline & 5.5 & 5.52 & 0.4 & 100.36 & & \\
\hline & 6.5 & 6.54 & 0.66 & 100.6 & & \\
\hline \multirow[t]{3}{*}{ PHE } & 2.5 & 2.51 & 0.48 & 100.48 & 0.383 & $100.13 \pm 0.381$ \\
\hline & 3.69 & 3.69 & 0.27 & 99.72 & & \\
\hline & 5.01 & 5.01 & 0.2 & 100.2 & & \\
\hline \multirow[t]{3}{*}{ TRD } & 2 & 2.04 & 2 & 102 & 0.968 & $100.9 \pm 0.967$ \\
\hline & 3.5 & 3.52 & 0.57 & 100.57 & & \\
\hline & 7.5 & 7.51 & 0.13 & 100.13 & & \\
\hline \multirow[t]{3}{*}{ IMT } & 3 & 3 & 0.00 & 100 & 0.295 & $100.9 \pm 0.298$ \\
\hline & 4.5 & 4.52 & 0.44 & 100.44 & & \\
\hline & 7 & 7.04 & 0.57 & 100.57 & & \\
\hline \multirow[t]{3}{*}{ VRP } & 4.2 & 4.21 & 0.23 & 100.23 & 0.474 & $100.14 \pm 0.475$ \\
\hline & 5.5 & 5.46 & 0.36 & 99.63 & & \\
\hline & 7 & 7.04 & 0.57 & 100.57 & & \\
\hline
\end{tabular}

To every pure drug sample, a known excipient of each drug is added and recovery experiments were performed, to test the selectivity of the drug. The methods have been tested for their ruggedness by two analysts using two different spectrophotometers.

\section{Factors affecting the absorbance effect of acid concentration}

A series of drug samples of $1 \mathrm{~mL}$ to $7 \mathrm{~mL}$ were taken in $10 \mathrm{~mL}$ volumetric flasks to carry out the reaction. To this series add 1 $\mathrm{mL}$ of $\mathrm{HCl}$ followed by $1 \mathrm{~mL}$ of Chloramine-T solution. These flasks were set aside for 10 minute with occasional shaking; later $1 \mathrm{~mL}$ of Indigo caramine dye was added, then completed to $10 \mathrm{~mL}$ total volume with water. Analysis of the data indicates that for $1.0 \mathrm{~mL}$ of $\mathrm{HCl}$, the maximum absorbance was noticed. In addition, with increase in the volume, decrease in the absorbance was noticed. Consequently, a volume of $1.0 \mathrm{~mL}$ of $\mathrm{HCl}$ was finalised for all measurements.

\section{Analysis of pharmaceuticals}

The following drug solutions were chosen in Beer's Law limit in order to test the applicability of the method developed. For this study 3.0,5.5,6.5 $\mu \mathrm{g} \mathrm{mL}^{-1}$ of GEM; 2.5,3.69,5.01 $\mu \mathrm{g} \mathrm{mL}^{-1}$ of PHE ; 2.0,3.5,7.5 $\mu \mathrm{g} \mathrm{mL}^{-1}$ of TRD; 3.0,4.5,7.0 $\mu \mathrm{g} \mathrm{mL}^{-1}$ of IMT; and 4.2,5.5,7.0 $\mu \mathrm{g} \mathrm{mL}^{-1}$ of VRP were selected. Table 1 shows the regression characteristics of the drugs. The analysis of each tablet is carried out thrice in order to calculate the precision and accuracy is estimated in terms of percent recovery and percent RSD. Table 4 shows the percent recovery from commercial formulation. The applicability of the developed method for the pharmaceutical analysis was confirmed from the obtained results such as excellent percent recovery and RSD being less than 2 for each drug. Further calculations of t-test and F-test values were carried out.

Table 4. Application of proposed method for the estimation of studied drugs in pharmaceutical formulations by oxidation using Chloramine$T$ and Indigo Caramine.

\begin{tabular}{|c|c|c|c|c|c|c|}
\hline Drug & $\begin{array}{l}\text { Taken } \\
(\underset{-1}{\mu})\end{array}$ & $\begin{array}{l}\text { Found } \\
(\underset{-1}{(\mu \mathrm{g}} \mathrm{mL}\end{array}$ & $\begin{array}{l}\mathrm{Er} \\
(\%)\end{array}$ & $\begin{array}{l}\text { Recovery } \\
\text { (\%) }\end{array}$ & $\begin{array}{l}\text { RSD } \\
\text { (\%) }\end{array}$ & $\begin{array}{l}\text { Proposed } \\
\text { method mean } \\
\pm S D\end{array}$ \\
\hline \multirow[t]{3}{*}{ GEM } & 3 & 3.011 & 0.366 & 100.36 & 0.138 & $100.14 \pm 0.137$ \\
\hline & 5.5 & 5.52 & 0.4 & 100.36 & & \\
\hline & 6.5 & 6.54 & 0.66 & 100.6 & & \\
\hline \multirow[t]{3}{*}{ PHE } & 2.5 & 2.51 & 0.48 & 100.48 & 0.383 & $100.13 \pm 0.381$ \\
\hline & 3.69 & 3.69 & 0.27 & 99.72 & & \\
\hline & 5.01 & 5.01 & 0.2 & 100.2 & & \\
\hline \multirow[t]{3}{*}{ TRD } & 2 & 2.04 & 2 & 102 & 0.968 & $100.9 \pm 0.967$ \\
\hline & 3.5 & 3.52 & 0.57 & 100.57 & & \\
\hline & 7.5 & 7.51 & 0.13 & 100.13 & & \\
\hline \multirow[t]{3}{*}{ IMT } & 3 & 3 & 0 & 100 & 0.295 & $100.9 \pm 0.298$ \\
\hline & 4.5 & 4.52 & 0.44 & 100.44 & & \\
\hline & 7 & 7.04 & 0.57 & 100.57 & & \\
\hline \multirow[t]{3}{*}{ VRP } & 4.2 & 4.21 & 0.23 & 100.23 & 0.474 & \\
\hline & 5.5 & 5.46 & 0.36 & 99.63 & & \\
\hline & 7 & 7.04 & 0.57 & 100.57 & & \\
\hline
\end{tabular}

From the Table 5 It is clear that the values of t-test and F-test are below the allowable range. This confirms the exceptional applicability of the methods for pharmaceutical analysis. The developed methods can be applied without interference to pharmaceutical analysis, which is indicated from the excellent recovery studies.

Table 5. Validation of method developed in comparison with standard published method.

\begin{tabular}{lll}
\hline Pharmaceuticals/Tablets & Student's t-test & F-test \\
\hline Gemifloxacin & 0.0577 & 1.754 \\
& $(1.440)^{*}$ & $(3.107)^{*}$ \\
\hline
\end{tabular}




\begin{tabular}{lll}
\hline Phenyl ephrine $\mathrm{HCl}$ & $\begin{array}{l}2.01 \\
(2.015)^{*}\end{array}$ & $\begin{array}{l}0.0271 \\
(3.404)^{*}\end{array}$ \\
\hline Tramadol & 0.793 & 3.875 \\
\hline & $(1.638)^{*}$ & $(5.309)^{*}$ \\
\hline Imatinibemeslate & 2.163 & 0.001 \\
& $(1.476)^{*}$ & $(3.45)^{*}$ \\
\hline Verapamil & 1.416 & 0.0306 \\
& $(1.638)^{*}$ & $(3.45)^{*}$ \\
\hline
\end{tabular}

*The values in the paranthesisare maximum permissible range of t-test and $\mathrm{F}$ test.

\section{Conclusion}

A novel, simple, accurate and precise method, which is applicable in ordinary laboratories was developed for the determination of GEM, PHE, TRD, IMT, VRP. Using this method, the drugs could be determined from frequently used excipients without intrusion, in tablet formulation. In this method, inexpensive and simple to prepare solvents were used. They could be used for routine drug analysis in a quality control laboratory.

\section{Acknowledgement}

We are grateful to Head, Department of Chemistry, Osmania University for providing facilities.

\section{References}

1. Jack C. Ewing's Analytical Instrumentation Hand book ( $3^{\text {rd }}$ edition) 2005.

2. Sara AME, Abdalla AE, Hassan YAE. Spectrophotometric methods for the determination of gemifloxacin in pharmaceutical formulations. Acta Pharm Sin B. 2011; 1: 248-253.

3. Gouda AA, Alaa SA, Ragaa ES, et al. Spectrophotometric determination of gemifloxacin mesylate, moxifloxacin hydrochloride, and enrofloxacin in pharmaceutical formulations using acid dyes. J Anal Methods Chem. 2014; 2014: 1-16.

4. Hassan SSU, Hayat U,Tariq I, et al. Spectrophotometric method for the determination of Gemifloxacin mesylate in pure and tablet dosage form. Pak J Pharm Sci. 2014; 27: 1171-1174.

5. Abdallah NA. HPLC and densitometric TLC methods for simultaneous determination of gemifloxacin with some coadministered drugs in human plasma. Chromat Separation Techniq. 2010; 5:9.

6. Marothu VK, Dannana GS. Spectrophotometric determination of gemifloxacin mesylate in pharmaceutical formulations through ion-pair complex formation. E J Chem. 2008; 5: 515-520.

7. Dalia Z, Omnia AI, Wafaa SH, et al. Rapid and validated HPLC-UV method for determination of gemifloxacin in human urine. Int J Pharm Pharm Sci. 2015; 7:104-108.
8. Noha NA, Ashraf MM, Salwa RE, et al. Development and validation of stability indicating HPTLC assay for determination of gemifloxacin mesylate in dosage forms. Int J Anal Chem. 2013; 1-11.

9. Mohammed GAW, Ragaa ES, Ayman AG, et al. Kinetic spectrophotometric determination of some fluoroquinolone antibiotics in bulk and pharmaceutical preparations. Bull Chem Soc Ethiop. 2013; 27: 329-346.

10. Sasikala M, Priyanka P, Vinod KT, et al. Spectrophotometric Estimation of Drugs Using N-Bromo Succinamide and Indigo Caramine Couple. Orient J Chem. 2016; 32: 617-625.

11. Prashanthi M, Charan ST, Venkateshwarlu G. Pharmaceutical analysis using N-Bromo succinamideamarnth dye couple: A spectrophotometric study. Int J Chemtech Res. 2014; 6: 400-408.

12. Cieri URJ. Determination of phenylephrine hydrochloride, chlorpheniramine maleate, and methscopolamine nitrate in tablets or capsules by liquid chromatography with two UV absorbance detectors in series. AOAC Int. 2006; 89: 53-57.

13. Hamide S, Tuncel O, Senyuva, H, et al. Simultaneous highperformance liquid chromatographic determination of paracetamol, phenylephrine $\mathrm{HCl}$, and chlorpheniramine maleate in pharmaceutical dosage forms. J Chromatogr Sci. 2002; 40: 97-100.

14. Palabıyı İM, Onur F. The Simultaneous Determination of Phenylephrine Hydrochloride, Paracetamol, Chlorpheniramine Maleate and Dextromethorphan Hydrobromide. Pharmaceut Preparat Chromatograph. 2007; 66: 93-96.

15. Nabeel SO, Noha TAFT. Indirect Spectrophotometric Determination of Phenylephrine Hydrochloride in Pharmaceutical Preparations. J Pure Sci. 2011; 16:67-74.

16. Seethamma M, Vijayakumar B, Prasad GS, et al. Extractive spectrophotometric methods for determination of esmolol hydrochloride using acidic triphenyl methane dyes. Asian J Chem. 2011; 4: 1789-1792.

17. Kucuk A, Kadioglu Y, Determination of tramadol hydrochloride in ampoule dosage forms by using UV spectrophotometric and HPLC-DAD methods in methanol and water media. Farmaco. 2005; 60: 163-169.

18. Nagaraja SK, Ramachar T, Chakravarthy IE, et al. A simple spectrophotometric estimation of tramadol hydrochloride in pharmaceutical formulations. Chem Sci Trans. 2012; 1: 317-320.

19. Aysel K, Yucel K. Determination of Tramadol Hydrochloride in Ampoule Dosage Forms by using UV Spectrophotometric and HPLC-DAD Methods in Methanol and Water Media. Il Farmaco. 2005; 60: 163-169.

20. Nagaraja SK, Prabhavathi K, Chakravarthi IE, et al. Spectrophotometric Determination of Tramadol Hydrochloride in Pharmaceutical Formulations. Chem Sci Rev Lett. 2013; 1: 168-171.

21. Xun Y, Jingkai Z, Jianguo L. Flow injection determination of Tramadol based on its sensitising effect on the 
chemiluminescent reaction of permanganate-sulfite. Am J Analyt Chem, 2011; 2: 768-775.

22. Caiyun Z, Tao L, Xiaoli Z, et al. Determination of Tramadol in Human Serum by Capillary Electrophoresis with the End-Column Electrochemiluminescence Detection. Open J Biophys. 2013; 3: 121-127.

23. Nabil B, Hala AA, Awami E, et al. Spectrophotometric determination of tramadol hydrochloride and diclofenac sodium in pharmaceuticals and environmental samples. Pharma Sin. 2013; 4: 10-16.

24. US national library of medicine, US.

25. Keating GM, Scott LJ. Moxifloxacin: A review of its use in the management of bacterial infections. Drugs. 2004; 64: 2347.

26. A-Elghany MF, Elkawy MA, Zeany BE, et al. High performance thin layer chromatography quantitation of isradipine in the presence of its degradation products. J Planar Chromatogr. 1996; 9 :290-292.

27. Violeta Z, Dragica S, Marina S, Trajce. HPLC method for determination of verapamil in human plasma after solidphase extraction, J Biochem Biophys Methods. 2008; 70: 1297-1303.

28. Sawicki W. A validated method for the determination of verapamil and norverapamil in human plasma $\mathrm{J}$ Pharmaceut Biomed. 2001; 25; 689-695.

29. Walash M, Belal F, El-Enany N Abdelsalam. Spectrofluorometric Determination of Verapamil Hydrochloride in Pharmaceutical Preparations and Human Plasma Using Organized Media: Application to Stability Studies. A J AOAC Int. 2006; 89: 1565-72.

30. Nafisur R, Md H. Spectrophotometric determination of verapamil hydrochloride in drug formulations with chloramine-T as oxidant. Anal Bioanal Chem. 2002; 374: 484-489.

31. Violeta I, Dragica Z, Marina S, et al. HPLC method for determination of verapamil in human plasma after solidphase extraction. J Biochem Biophys Methods. 2008; 70: 1297-1303.

32. Scott MJ, Shoukry KWK. An HPLC Method for the Determination of Verapamil and Norverapamil in Human Plasma. J liq chromat. 10; 1987: 1187-1201.

33. Sohail M, Guanhong X, Fangdi W, et al. Determination of Verapamil $\mathrm{HCl}$ in Pharmaceutical Preparations by a Fluorescent Nano Probe Based on CdTe/CdS/ZnS Quantum Dots. Nanomat. 2017; 7: 35.

34. Nafisur R, Syed NHA. Spectrophotometric method for the determination of verapamil hydrochloride in pharmaceutical formulations using $\mathrm{N}$-bromosuccinimide as oxidant. Il Farmaco. 2004; 59: 529-36.
Hyderabad

India

E-mail: venkateshwarlugoud@yahoo.com

\section{*Correspondence to:}

Venkateshwarlu Gandu

Department of Chemistry

Osmania University 